\title{
ABORDAGENS DA DITADURA MILITAR: PONDERAÇÕES ACERCA DO ENEM E DO ENSINO DE SOCIOLOGIA
}

\section{ENFOQUES DE LA DITADURA MILITAR: PONDERACIONES ACERCE DEL ENEM Y DE LA ENSEÑANZ DE SOCIOLOGÍA}

Karlla Christine Araújo Souza Raiara Luana da Silva Nascimento

\section{RESUMO}

A Ditadura Militar, iniciada em 1964 e que dominou o poder no Brasil até 1985, tem sido um tema abordado no Exame Nacional do Ensino Médio (Enem), conforme aponta estudo realizado pelo Programa Institucional de Bolsas de Iniciação à Docência (PIBID) do curso de Ciências Sociais da Universidade do estado do Rio Grande do Norte/UERN. A Ditadura Militar foi um regime marcado pela coerção à democracia, supressão de direitos constitucionais, perseguição à política social e repressão a intelectuais, artistas e todas as pessoas que opinassem e estivessem contra o regime. O Golpe Militar de 1964 ocorreu um tempo após Jânio Quadros renunciar à presidência, quando seu vice João Goulart assumiu o governo dando início as reorganizações políticas e sociais. Estudantes, organizações populares e trabalhadores conseguiram espaços em todo o cenário político preocupando as classes conservadoras, como empresários e banqueiros. Até mesmo os Estados Unidos começaram a temer que o Brasil se voltasse para o regime comunista em plena guerra fria. Os partidos que estavam se opondo a João Goulart o acusavam de estar planejando um golpe esquerdista e que ele era o principal responsável pelos problemas que o Brasil enfrentava na época. Por causa desta pressão, João Goulart resolveu fazer um grande comício para a população na central do Brasil onde defendeu as reformas da base proletária e prometeu que iria fazer 
ABORDAGENS DA DITADURA MILITAR: PONDERAÇÕES ACERCA DO ENEM E DO ENSINO DE SOCIOLOGIA

Karlla Christine Araújo Souza

Raiara Luana da Silva Nascimento

mudanças na educação e economia do país. Mas João Goulart foi reprimido pela crise política e tensões sociais. Com essa situação Goulart saiu do país, se refugiando no Uruguai. Os militares tomaram conta do poder com várias leis que suprimiam direitos, inclusive de cassa a mandatos e suspensão dos direitos políticos. Durante esse regime houve um grande aumento do poder central, passaram a controlar toda a sucessão presidencial indicando os presidentes militares. Este trabalho tem por objetivo realizar um estudo acerca da profundidade das questões do ENEM que abordam o referido tema. A necessidade deste estudo surgiu a partir de uma atividade realizada pelo PIBID Ciências Sociais, com a elaboração de uma prova chamada PASSE, baseada nas provas do ENEM, e a aplicação da mesma nas escolas parceiras deste programa. Ao final do estudo, serão feitas considerações sobre a abordagem do tema tendo como critério a visão crítico-reflexiva exigida para ensino das ciências sociais no ensino médio.

Palavras-chave: Ditadura Militar. Ensino. PIBID. PASSE.

\section{RESUMEN}

La Dictadura Militar que tuvo inicio en 1964 y dominó el poder en Brasil hasta 1985 ha sido un tema abordado en el Examen Nacional de la Enseñanza Media (ENEM), según ha señalado estudios realizados en el campo de la Ciencias Sociales por el Programa de Bolsa e Iniciação à docência (PIBID) de la Universidad del Estado de Rio Grande do Norte (UERN). La Dictadura Militar fue un régimen marcado por la coerción a la democracia, supresión de derechos constitucionales, persecución a la política social y represión a intelectuales, artista y todas las personas que opinaran y estuvieran en contra al régimen. El Golpe Militar de 1964 ocurrió un tiempo después que Jânio Quadros renunció a la presidencia, cuando su vice João Goulart asumió el gobierno dando inicio a las reorganizaciones políticas y sociales. Estudiantes, 


\section{ABORDAGENS DA DITADURA MILITAR: PONDERAÇÕES ACERCA DO ENEM E DO ENSINO DE SOCIOLOGIA}

Karlla Christine Araújo Souza

Raiara Luana da Silva Nascimento

organizaciones populares y trabajadores lograron espacio en todos los escenarios políticos, preocupando a las clases conservadoras, como empresarios y banqueros, incluso Estados Unidos empezó a temer que Brasil se volviera hacia el régimen comunista en plena guerra fría. Los partidos que estaban oponiéndose a João Goulart lo acusaban de estar planeando un golpe izquierdista, lo cual sería el principal responsable de los problemas que Brasil enfrentaba en la época. Presionado, João Goulart resolvió hacer un gran motín en la central de Brasil, una región alrededor de la estación de trenes en Rio de Janeiro, donde defendió las reformas de la base proletaria y prometió hacer cambios en el área de la Educación y economía del país, pero fue reprimido por la crisis política y las tensiones sociales, situaciones que lo hizo salir del país y refugiarse en Uruguay. Los militares tomaron el poder instaurando varias leyes que suprimían derechos, permitiéndolos, incluso, la anulación de mandatos y la suspensión de derechos políticos. En este periodo hubo un aumento significativo del poder central, pues contralaban toda la sucesión presidencial, indicando militares para ocupación del puesto. Bajo esta perspectiva, este trabajo tiene como objetivo realizar una investigación acerca de la profundidad de las cuestiones del ENEM que abordan el tema. La necesidad de explorar este tema surgió a partir de una actividad deI PIBID Ciencias Sociales con la elaboración de un Examen titulado PASSE, que está basado en pruebas del ENEM, aplicado en las escuelas asociadas al programa. Al final, se realizarán consideraciones sobre el abordaje de la temática, teniendo como criterio la visión crítica y reflexiva exigida para la Enseñanza de las Ciencias Sociales en la Enseñanza Media.

Palabras clave: Dictadura militar. Enseñanza. PIBID. PASSE. 
ABORDAGENS DA DITADURA MILITAR: PONDERAÇÕES ACERCA DO ENEM E DO ENSINO DE SOCIOLOGIA

Karlla Christine Araújo Souza

Raiara Luana da Silva Nascimento

\section{INTRODUÇÃO}

Este artigo tem o intuito de demonstrar abordagem da Ditadura Militar com ponderações acerca do ENEM e do Ensino de Sociologia. Muito se tem discutido, recentemente, acerca da natureza de um golpe de estado, lembrando o atual cenário político e o fato de que o Brasil foi marcado pelo golpe Militar de 1964-1985, uma época marcada pela falta de democracia, suspensão de direito constitucionais, na qual quem ficasse contra o regime Militar era perseguido e torturado.

Durante o regime Militar, que vigorou entre 1964 e 1985, houve um grande aumento do poder central em especial o executivo, o comando das forças armadas passou a controlar toda sucessão presidencial indicando os candidatos militares com o apoio do congresso nacional, com isso o povo não tinha liberdade de expressão, suas opiniões eram reprimidas e os proletários sofriam com altos juros e aumento da inflação.

Tendo em vista o estado de exceção que estamos atravessando em virtude do impeachmeant da presidente eleita Dilma Roussef (PT), e do governo interino do presidente Michel Temer (PMDB), O PIBID Ciências Sociais refletiu sobre a importância de avaliar como os alunos do ensino médio, que irão se submeter ao Exame Nacional do Ensino Médio-ENEM, irão se deparar com este tema, isto é, como as questões estão sendo abordadas, e que visão dos fatos elas apresentam.

O ENEM foi criado pelo MEC com o intuito de avaliar e certificar a conclusão do ensino médio tanto para rede privadas quanto a pública, servindo como teste para ingressar nas mais diversas universidades do país. Através de uma prova chamada de PASSE (Prova aulão de Sociologia sobre o Enem), pensada pelos alunos de licenciatura do programa PIBID de Ciências Sociais da Universidade do Estado do Rio Grande do Norte UERN, Mossoró-RN, os professores em formação analisam as questões do ENEM como forma de 
ABORDAGENS DA DITADURA MILITAR: PONDERAÇÕES ACERCA DO ENEM E DO ENSINO DE SOCIOLOGIA

Karlla Christine Araújo Souza

Raiara Luana da Silva Nascimento

discutir o conhecimento das ciências sociais e problematizar as questões do exame nacional.

Primeiramente os alunos fazem um levantamento das questões do ENEM que tenham abrangência no campo das Ciências Sociais, englobando as três áreas: Sociologia, Antropologia e a Ciência Política. Dentre esses temas foi visto que a Ditadura Militar nos últimos anos tem sido razoavelmente abordada na prova do ENEM. No entanto, foi na prova de 2014 que houve incidência de maior quantidade de questões, pois no dia 31 de março de 2014 foi marcado por 50 anos do golpe militar no Brasil.

Pensado nas semelhanças entre o golpe militar no Brasil e o atual estado de exceção, na importância do ENEM e na presença da sociologia no ensino médio, os licenciandos selecionaram algumas questões e levaram as escolas parceiras do programa PIBID, onde foram discutidas com os alunos da rede pública do ensino médio e problematizado o porquê de estas questões serem discutidas na atualidade.

Desse modo, trazer ao aluno a discussão sobre o tema Ditadura Militar no Brasil, tinha por objetivo dar aos jovens estudantes a ciência sobre as práticas de tortura e repressão, as medidas governamentais que caracterizaram este regime e os movimentos de protesto oprimidos, dando aos alunos a possibilidade de desenvolver o senso crítico e formar suas opiniões.

\section{DITADURA MILITAR}

O golpe militar de 1964 ocorreu um tempo após Jânio Quadros renunciar a presidência, quando seu vice João Goulart assumiu em um clima totalmente tenso. No seu governo aconteceu a abertura das organizações sociais, estudantes, organizações populares e trabalhadores conseguiram espaços em no cenário político. Setores da sociedade, como a classe média e segmentos religiosos, temiam o avanço do movimento comunista, em quem o presidente buscava cada vez mais apoio. Latifundiários ficaram preocupados com a 


\title{
ABORDAGENS DA DITADURA MILITAR: PONDERAÇÕES ACERCA DO ENEM E DO ENSINO DE SOCIOLOGIA
}

\author{
Karlla Christine Araújo Souza \\ Raiara Luana da Silva Nascimento
}

reforma agrária e a tensão que ela poderia gerar no campo. Empresas multinacionais se sentiram prejudicadas com os limites impostos à remessa de lucros para o exterior. Os militares também passaram a apontar o perigo que as mobilizações populares representavam para a democracia, ao subverterem a ordem e a paz, e a nação imperialista dos Estados Unidos começaram a temer que o Brasil se voltasse para o lado comunista em plena Guerra Fria. Assim, tais preocupações ascendiam à condição de justificativa para que medidas arbitrárias fossem encampadas com autoritarismo político. Valle relata como o Conselho de Segurança Nacional passa a examinar a "ameaça comunista" no Brasil e a crise do seu balanço de pagamentos:

\begin{abstract}
Ao que tudo indica, naquela oportunidade, decidiu-se que os Estados Unidos suspenderiam totalmente qualquer financiamento ao Governo Goulart, nada fazendo, como prorrogação de vencimentos para aliviar as dificuldades de suas contas externas, e só destinando recursos aos Estados, depois denominados "ilhas de "Sanidade administrativa", cujos governadores eram militantes anticomunistas (VALLE, 2014, p.17).
\end{abstract}

Os partidos políticos que estavam se opondo a João Goulart o acusavam de estar planejando um golpe esquerdista e que ele era o principal responsável pelos problemas que o Brasil estava enfrentando na época. No dia 13 de março de 1964, João Goulart realiza um grande comício na Central do Brasil (Rio de Janeiro), onde defende as Reformas de Base. Neste plano, Jango prometia mudanças radicais na estrutura agrária, economia e educação do país, a fim de apaziguar a situação.

A crise política e as tensões sociais estavam apenas aumentando, foi quando, seis dias depois, em 19 de março, os conservadores organizam uma manifestação contra as intenções de João Goulart, denominada Macha da Família com Deus pela Liberdade, que reuniu milhares de pessoas pelas ruas do centro da cidade de São Paulo. O clima de crise política e as tensões sociais aumentavam a cada dia. No dia 31 de março de 1964, tropas de Minas 
ABORDAGENS DA DITADURA MILITAR: PONDERAÇÕES ACERCA DO ENEM E DO ENSINO DE SOCIOLOGIA

Karlla Christine Araújo Souza

Raiara Luana da Silva Nascimento

Gerais e São Paulo saíram às ruas. Para evitar uma guerra civil, João Goulart deixa o país refugiando-se no Uruguai. A partir daí os militares tomam o poder.

Foram criando vários atos Institucionais, em 9 de abril é decretado o Ato Institucional Número 1 (Al-1) no qual as primeiras medidas repressivas foram tomadas logo depois do golpe, com cassações de mandatos, suspensão de direitos políticos, demissões de funcionários públicos e expulsão de militares das Forças Armadas. A Operação Limpeza buscou eliminar todos os elementos identificados com o período anterior ou considerados ameaçadores para os objetivos do novo regime.

Durante esse regime houve um grande aumento do poder central, em especial o executivo. O comando das forças armadas passou a controlar toda a sucessão presidencial indicando os candidatos militares com 0 apoio do Congresso Nacional. A liberdade de expressão era quase inexistente, tudo que era comum no governo normal, como os partidos políticos, estudantis e outras organizações que favorecia a classe do proletariado, foram extintas ou sofreram intervenções do governo.

Já no primeiro Ato Institucional, de 09 de abril de 1964, a mudança institucional especificava-se, desde logo, por um traço característico: o deslocamento do poder constituinte do povo (todo o poder emana do povo e em seu nome será exercido - Constituição de 1946, art.1) para a revolução: (...). A revolução vitoriosa - declarava o preâmbulo do A to Institucional ํํ I - se investe no exercício do Poder Constituinte. Este se manifesta pela eleição popular ou pela revolução.

Esta é a forma mais expressiva e mais radical do Poder Constituinte. Assim, a revolução vitoriosa, como o Poder Constituinte, se legitima por si mesma. Ela destitui o governo anterior e tem a capacidade de constituir o novo governo.

Segundo Rezende (2013), o deslocamento da apropriação do Poder Constituinte em favor de uma camada dirigente passava a ser justificada em si mesma, sem prestar contas ao povo, alheio a qualquer responsabilidade 
ABORDAGENS DA DITADURA MILITAR: PONDERAÇÕES ACERCA DO ENEM E DO ENSINO DE SOCIOLOGIA

Karlla Christine Araújo Souza

Raiara Luana da Silva Nascimento

perante a nação. É inegável que no plano da nova ordem institucional foi exatamente isto que ocorreu. Porém, tanto o primeiro Ato Institucional quanto os demais atos e/ou medidas e ações não apareciam desta forma. Ou seja, o regime lutava para construir um sistema de valores e ideias visando sedimentar na sociedade como um todo, a crença de que o movimento de 1964 somente se legitimava porque ele expressava sob todos os aspectos os interesses do povo brasileiro. (REZENDE, 2013)

Em 1965 o Al-2 determinava eleições indiretas para a presidência, além de extinguir todos os partidos políticos, formando apenas dois: a Aliança Renovadora Nacional (ARENA), dos militares e o Movimento Democrático Brasileiro (MDB), da oposição. Com o Al-2, somente as eleições presidenciais seriam indiretas, mas em 1966, o governo editou o AI-3, determinando eleições indiretas também para os governos dos estados, além da indicação, pelo governador, dos prefeitos das capitais. O Al-4, também de 1966, convocou o congresso para elaborar a nova constituição. Nesse período, houve também a substituição do presidente Castelo Branco, pelo general Costa e Silva, que havia sido eleito pelo Congresso nacional em outubro de 1966. O general assumiu o cargo em 15 de março de 1967. O ato Institucional Número 5 (AI- 5). Este foi o mais duro do governo militar, pois aposentou juízes, cassou mandatos, acabou com as garantias do habeas-corpus e aumentou a repressão militar e policial.

\section{O RETORNO À DEMOCRACIA}

O Brasil apresentava vários problemas, tais como elevada inflação e a recessão também. Enquanto isso a oposição ganha terreno com o surgimento de novos partidos e com o fortalecimento dos sindicatos. Em 1984, políticos de oposição, artistas, jogadores de futebol e milhões de brasileiros participam do movimento das Diretas já. O movimento era favorável à aprovação da Emenda Dante de Oliveira que garantiria eleições diretas para presidente naquele ano, 
ABORDAGENS DA DITADURA MILITAR: PONDERAÇÕES ACERCA DO ENEM E DO ENSINO DE SOCIOLOGIA

Karlla Christine Araújo Souza

Raiara Luana da Silva Nascimento

mas não foi aprovada. No dia 15 de Janeiro de 1985, o Colégio Eleitoral escolheria o deputado Tancredo Neves, que concorreu com Paulo Maluf, como novo presidente da República. Ele fazia parte da Aliança Democrática - 0 grupo de oposição formado pelo PMDB e pela Frente Liberal. Em 1988 é aprovada uma nova constituição para o Brasil. A Constituição Federal em 1988 apagou os rastros da ditadura militar, o sofrimento e repressão foram amainados, se estabelecendo assim novos princípios de democracia no país.

\section{O PASSE E O PIBID CIÊNCIAS SOCIAIS}

No desenvolvimento da prova PASSE pelos bolsistas PIBID Ciências Sociais, são reunidos dados com base teórica necessária para fundamentar as discussões acerca das questões da prova, as mesmas são debatidas nas reuniões do PIBID. Para isso, faz-se a análise das provas anteriormente aplicadas pelo Exame Nacional do Ensino Médio-ENEM, avalia-se a interdisciplinaridade em anos diferentes de aplicação, identificando-se as questões pertinentes ao conhecimento das ciências sociais e presença deste conteúdo no currículo do PIBID Ciências Sociais para o Ensino Médio.

A elaboração da prova "PASSE" ocorre em duas etapas: a primeira parte se constitui de análise das questões das provas oficias do ENEM, discutidas em pequenos grupos para que sejam selecionados temas relevantes às ciências sociais. Em seguida, as questões são escolhidas por meio de alguns critérios: as questões melhores elaboradas, questões que se agrupam em temáticas afins, e temas mais recorrentes em todas as provas. Ao final, é preciso chegar a uma quantidade de questões que seja adequada ao tempo que temos na sala de aula, uma média de 25 questões são selecionadas e divididas entre o grupo para chegar ao resultado final de uma prova com 25 questões.

A segunda parte da atividade se dá com a aprendizagem sobre o conteúdo, o grande grupo é subdividido em pequenos grupos para estudar os 


\section{ABORDAGENS DA DITADURA MILITAR: PONDERAÇÕES ACERCA DO ENEM E DO ENSINO DE SOCIOLOGIA}

Karlla Christine Araújo Souza

Raiara Luana da Silva Nascimento

referenciais teóricos relacionados a cada tema que foi selecionado na primeira parte, para então ter o domínio da explicação durante a aplicação da prova nas escolas.

Após passar pelas etapas anteriores, ocorre o contato direto com os alunos da rede pública de ensino das escolas parceiras do programa, para debatermos as questões em forma de simulado, distribuirmos gabarito e chegarmos às alternativas corretas junto aos alunos. Dessa maneira, criamos uma interação com a turma, envolvendo-os de forma significativa num debate coletivo de caráter sociológico para incentivá-los ao senso crítico que a própria sociologia requer para a compreensão das questões e da vida em sociedade.

A magia entre o ensinar e aprender se faz presente pela troca mútua de conhecimentos que é obtido durante a aplicação como o próprio Educador Paulo Freire menciona: "Ensinar não é transmitir conhecimento, mas criar as possibilidades para a sua produção ou a sua construção. Quem ensina aprende ao ensinar e quem aprende ensina ao aprender" (FREIRE, 2002, p.12).

Perceber o envolvimento do aluno e seu interesse cada vez maior pela sociologia, na perspectiva que este pode assimilar o conteúdo da disciplina de sociologia para o melhor aprendizado e para um bom desempenho no ENEM, tem sido de grande satisfação para todos nós que realizamos essa atividade.

O tema Ditadura Militar sempre esteve presente na prova do ENEM, mas foi no ano de 2014 que se destacou, pois foi no dia 31 de março de 2014, que completou-se 50 anos do golpe militar no Brasil, uma época marcada pela repressão dos direitos humanos e da igualdade, quando muitas pessoas foram torturadas e morreram por não aceitarem um governo golpista.

No que se refere ao conteúdo de Ciências Humanas e suas Tecnologias, o candidato deve ser capaz de recorrer a tudo que estudou no decorrer do Ensino Médio para melhor interpretar os enunciados das questões propostas. No entanto, sobre o tema da ditadura militar, percebemos que não há tanta profundida acerca do conhecimento necessário para responder as questões. 
ABORDAGENS DA DITADURA MILITAR: PONDERAÇÕES ACERCA DO ENEM E DO ENSINO DE SOCIOLOGIA

Karlla Christine Araújo Souza

Raiara Luana da Silva Nascimento

Elas são de caráter interpretativo e, na maioria dos casos, acompanhadas por charges e elementos ilustrativos, não permitindo que o teor da questão tenha aparência políica e requeira grande nível de conhecimento acerca de tema tão grave para a construção da cidadania.

\section{CONSIDERAÇÕES FINAIS}

Diante do exposto, fica evidente que a Ditadura Militar foi um período que marcou a história do Brasil por um golpe que reuniu as forças militares e tomaram o poder do presidente eleito. Exatamente 52 anos depois, milhares de brasileiros saem às ruas para pedir a saída da presidente Dilma Rousseff, em meio à crise política e com a ameaça real do impeachment, pois ela, assim com Goulart, não tinha apoio para aprovação de projetos, pois, novamente, militares, religiosos e partidos corruptos envolvidos em escândalos políticos não apoiam seu governo por alegar favorecer a classe popular. Assim como Goulart, a presidente Dilma sofreu o golpe, de acordo com sentença final do Tribunal Internacional pela Democracia no Brasil sobre a legalidade do processo de impeachment que afastou a presidente eleita Dilma Rousseff. $O$ evento reuniu juristas de vários países (México, da França, da Itália, da Espanha, da Costa Rica e dos EUA) no Rio Janeiro e divulgou o resultado desta investigação no dia 20 de outubro de 2016.

A decisão do corpo de jurados afirma que o processo violou todos os princípios do processo democrático e da ordem constitucional brasileira, bem como da Convenção Americana de Direitos Humanos e o Pacto Internacional de Direitos Civis e Políticos. Para definir se houve ou não golpe de estado, a comissão analisou cinco critérios: 1 . Viola a Constituição?; 2 . Sem a ocorrência de crime de responsabilidade, caracteriza um golpe parlamentar?; 3. Foram violados os tratados internacionais dos quais o Brasil é signatário?; e, 4. Impeachment deve ser declarado nulo? A decisão deste tribunal deverá ser levada ao conhecimento dos senadores brasileiros. 
ABORDAGENS DA DITADURA MILITAR: PONDERAÇÕES ACERCA DO ENEM E DO ENSINO DE SOCIOLOGIA

Karlla Christine Araújo Souza

Raiara Luana da Silva Nascimento

A despeito de ser considerado ilegítimo, o governo interino de Michel Temer tem lançado uma série de medidas arbitrárias como a MP 746, a PEC 241 e a PEC 55, que autorizam mudanças bruscas na educação e na saúde, restringindo os direitos civis e sociais sob a justificativa de cortes orçamentários, mesmo tendo salários e benefícios de juristas e parlamentares mantidos e/ou aumentados.

Esta comparação é importante de ser realizada e mesmo que a prova do ENEM não abra espaço para discussão aprofundada, a atividade realizada pelo PIBID Ciências Sociais possibilitou essa reflexão crítica e trouxe à tona um conteúdo de relevância política e social urgente para a juventude brasileira.

\section{REFERÊNCIAS}

ALVES, Márcio. 68 Mudou o Mundo. Rio de Janeiro: Nova Fronteira, 1993. BRASIL. Ministério da Educação (MEC). Orientações Curriculares para o Ensino Médio. Brasília: MEC/SEB,2006.

FREIRE, Paulo. Pedagogia da autonomia: saberes necessários à prática educativa. 21 ed. São Paulo. Editora Paz e Terra, 2002.

NAPOLTANO, Marcos. 1964: Historia do Regime Militar Brasileiro. São Paulo: Editora Contexto, 2014.

REZENDE, Maria. A Ditadura Militar no Brasil, repressão e pretensão de legitimidade 1964- 1984 . Londrina: Eduel, 2013.

Redação Click Política. DILMA É INOCENTADA: Tribunal Internacional conclui trabalhos e afirma que impeachment de Dilma é golpe. Disponível em http://clickpolitica.com.br/brasil/dilma-e-i nocentada-tribunal-internacional conclui-trabalhos-e-afirmam-que-impeachment-de-dilma-e-golpe/. Acesso em 01 nov. 2016.

VALLE, Maria. 1964-2014: Golpe Militar, História, Memória e Direitos Humanos. São Paulo: Laboratório Editorial da FCL, 2014 